Da sich hierbei die gleiche Abhängigkeit der Widerstandsfähigkeit von der Zusammensetzung ergab, so können wir uns hinsichtlich dieser Abhandlung mit dem Hinweise auf das Original begnügen.

Die Firma Max Kähler und Martini ${ }^{1}$ ) in Berlin bringt neuerdings Glasgefässe in den Handel, deren Zusammensetzung den auf Grund obiger Forschungen zu stellenden Anforderungen entspricht.

Vergleichungen von Quecksilberthermometern hat H. F. Wi e b e ${ }^{2}$ ) mit dem von ihm in dieser Zeitschrift 30, 1 beschriebenen Apparate ausgeführt. Da die Ergebnisse derselben nur in ihrer Ausführlichkeit von Werth sind, so müssen wir uns auf die Erwähnung der. Cntersuchungen beschränken.

W. Pomplun ${ }^{3}$ ) hat einen in dieser Zeitschrift 30,6 von Wiebe bereits angedeuteten Apparat zur Thermometervergleichung beschrieben, welcher anf dem Princip beruht, unter Anwendung von wenigen Flüssigkeiten, die in ihrer Zusammensetzung auch bei längerem Sieden sicher unverändert bleiben, beliebige Temperaturen constant $\mathrm{zu}$ erhalten, indem man den Siedepunkt dieser Flüssigkeiten durch Druckveränderung variirt.

Letzterer Zweck wird dadurch erreicht, dass das äussere Ende des Rückflusskühlers an einem Siedeapparat, äbnlich dem von Wieb e a. a. 0 . beschriebenen, mit einem zum Reguliren dienenden $Z$ wischengefäss verbunden ist, in welchem durch eine Luftpumpe eine beliebige Druckverminderung und bis zu einer gewissen Grenze auch eine Druckvermehrung hervorgerufen werden kann. Hinsichtlich der speciellen Einrichtungen, namentlich der Art der luftdichten Einsetzung der Thermometer in den Deckel des Siedegefässes, müssen wir auf das Original verweisen.

\title{
Zur Ausführung von Reactionen bei hoher Temperatur und
} hohem Druck bringt W. Hempel ${ }^{4}$ ) eine Vorrichtung in Vorschlag, welche dem vorliegenden $Z_{w e c k}$ in jeder Weise entsprechen soll.

Um die beim Erhitzen von aussen auftretende Schwierigleit zu umgehen, dass Eisengefässe, welche bei nur mässig gesteigerter Hitze genügende Festigkeit zeigen, bei Rothgluth bereits zu erweichen beginnen und deshalb keinen hohen Druck ertragen, bewirkt der Verfasser die Erhitzung auf elektrischem Wege im Innern des Apparates, während

1) Circular der Firma.

2) Zeitschrift für Instrumentenkunde 10, 435 .

3) Zeitschrift für Instrumentenkunde 11, 1.

4) Ber. d. deutsch. chem. Gesellsch. zn Berlin 23, 3388. 
die äusseren Wände durch Einlegen der ganzen Vorrichtung in kaltes Wasser gekühlt und so widerstandsfähig erhalten werden. Die Vorrichtung schliesst sich demnach an den ron W: Siemens angegebenen elektrischen Schmelzofen an. Als. Heizquelle bedient sich der Verfasser jedoch nicht des elektrischen Flammenbogens, sondern einer dem elektrischen Glühlicht entsprechenden Vorrichtung.

Der Apparat besteht aus einem Cylinder, welcher aus einem Stück Stahl gebohrt ist und durch einen verschraubbaren, mit einem Ventil versehenen Kopf verschlossen wird. In diesem Cylinder befindet sich eine zur Aufnahme der Substanz dienende Porzellanröhre, welche durch entsprechend gearbeitete Kohlenstiucke verschlossen wird. Diese sind unter sich durch einen mitten durch die Porzellanröhre gehenden, etwa $3 m m$ dicken Kohlenstab verbunden. Zu dem oberen Kohlenstück führt ein Kupferdraht, der durch den Kopf des Cylinders hindurchgeht und von diesem durch eine Röhre aus Hartgummi isolirt ist. Ein zweiter dicker Kupferdraht führt unten an den Autoclaven, so dass der Strom durch diesen in das untere Kohlenstück, durch den dünnen Kohlenstab nach dem oberen Kohlenstück und so zu dem oberen Kupferdraht geht.

Hinsichtlich der mit Hülfe dieser Vorrichtung ausgeführten Versuche verweisen wir auf das Original.

Zur Kennzeichnung der Flamme hat Ni c. Teclu ${ }^{1}$ ) Beiträge geliefert. Seine Untersuchungen wurden in dem von Karl Heumann angegebenen, sowie in selbst construirten Apparaten ausgeführt, auf deren Beschreibung wir jedoch verzichten müssen. Der Verfasser zeigt, wie sich eine leuchtende Leuchtgasflamme, die durch Verbrennung von nicht mit Luft gemischtem Gas entsteht, durch von unten her erfolgenden Zutritt atmosphärischer Luft unter geeigneten Umständen in zwei Flammen spalten kann, von denen die eine an der Mündung des Brenners fortbrennt, während die andere sich nach abwärts bewegt. Die Abwärtsbewegung hängt ganz von der Zuführung der atmosphärischen Luft ab und zwar ist dieselbe um so schneller, je grösser die Luftzufuhr ist. Hierdurch erklärt der Verfasser sehr gut das bekannte Zurückschlagen der Flammen. Durch Wiederzuführung grösserer Mengen Leuchtgas geht die bis dahin sich abwärts bewegende Flamme bald wieder aufwärts. Durch wechselnde Zuführung von Luft und Leuchtgas kann demnach ein Nähern oder Entfernen beider Flammenkegel stattfinden.

1) Journ. f. prakt. Chemie [N. F.] 44, 246. 